\title{
Considerations for Industry-Wide Certification of Training in the Oil and Gas Sector of Scotland
}

Rulzion Rattray, Oil \& Gas Academy of Scotland, United Kingdom

\begin{abstract}
:
This paper aims to evaluate the argument for implementing the concept of industrywide certification of training programmes in the oil and gas sector. The main emphasis is being made on the demand and challenges in implementing the industry-wide evaluation of training. This paper introduces an accessible framework of credit rating, which would provide a robust, internationally recognised, quality-assured credit system for industry-relevant courses.
\end{abstract}

Paper type: Conceptual paper

Keywords: Credit-rating, Certification, Training, Oil and Gas Industry, Accreditation, Accredited Training, OGAS 


\section{Introduction}

Established in 2012 to support Scottish Government objectives for the Energy Sector, the Oil and Gas Academy of Scotland (OGAS) is focussed on working with established oil and gas education and training providers and draws on the extensive professional and academic expertise available in Scotland with a view to providing a one stop shop for all oil and gas training and education and training requirements.

OGAS represents the collaborative efforts of a consortium of six organisations, all involved in education and training relevant to the oil and gas industry: the University of Aberdeen, Robert Gordon University, Heriot-Watt University, North East Scotland College, Forth Valley College and ASET International Oil and Gas Training Academy.

The oil and gas sector is of crucial international importance as well as being a vital part of the Scottish and UK economies. OGAS is focussed on the training and education requirements of the industry in support of the objectives of the Scottish Government through a process of collaboration and cooperation with all stakeholders in the sector.

Each of the OGAS partner institutions, based on their extensive and leading-edge oil \&gas knowledge and experience, as well as the broader professional skill sets available in Scotland, deliver world class training and education to support the oil and gas and wider energy sectors. Collectively, OGAS partners deliver a wide range of training and education for the industry, from craft level technician training through to postgraduate degrees and doctoral research. In addition to the existing, extensive range of training and education programmes provided by the OGAS partner organisations, OGAS also works with industry partners to develop specialist, tailored programmes for groups of professionals and for in-company training and education purposes.

The oil \&gas industry is typified by the large number of non-credit rated training courses being delivered for a wide variety of audiences and purposes from specialist, incompany coursesto commercial training companies selling broader-based courses to companies and individuals in the industry. These courses vary significantly in terms of quality, level and focus. This paper aims to outline the importance of developing an accessible framework of credit rating that will provide a robust, internationally recognised, quality-assured credit system for industry relevant courses. Furthermore it will be argued that the establishment of this framework will provide a solid basis for collaboration and cooperation between industry players and the education institutions represented by OGAS.

\section{Accreditation, Quality Assurance and Credit Rating}

The term 'accreditation' typically refers to 'a form of qualified status or individual registration awarded by a professional or regulatory body' which confirms that an organisation or individual is fit to practice certain crafts or disciplines (Lester, 2010).Accreditation can regulate or relate to a main discipline (e.g. human resource management or surveying) as well as to a secondary or sub-discipline (e.g. HR administration or quantity surveying). The key importance of accreditation is in its

International Journal of Management and Applied Research, 2015, Vol. 2, No. 3 
regulatory or normalising effect on the sector and on accreditation of training providers and their respective training courses. Overall, accreditation is the process by which it is determined whether an awarding body satisfies the regulatory principles and accreditation criteria necessary to successfully award and certificate a given unit or qualification (Harvey and Williams, 2010).

Quality of training courses is a flexible concept, hence the baseline of the meaning of it needs to be established. Van den Berghe (1996) suggests distinguishing between the 'quality of design' and 'quality of conformance' concepts. Quality of design refers to 'the capacity of an organisation to design, plan and specify products and services which will be considered to be of quality by the end-users' (ibid: 5). The end users in the case of the oil and gas sector are not the individual trainees but their respective employers or oil and gas operators, both national and international. Therefore, the operators would be more interested in two aspects of quality of conformance: a) 'the ability of an organisation to meet the design, planning and specifications' relevant for a particular profession, and b) 'the capacity of a training provider to deliver the programme' that meets technical specifications associated with a particular profession or the field of knowledge.

Another aspect often associated with the quality of training courses is meeting the expectations and/or customer satisfaction of trainees and their employers (Soares et al., 2013). Both trainees and their employers may have different expectations, hence there is a need for considering quality assurance in the context of accreditation. While the expectations of trainees (recipients of training) can be relatively easily measured and quantified to establish a benchmark of quality, the expectations of oil and gas operators seems to be more complex. The latter can also be measured but rather indirectly as the presence of a corporate performance management system would interfere with the benchmarking process.

Van den Berghe (1996) suggests formulating the industrial quality strategy based on the following principles:

- implementation of the (training) scheme within the deadline

- comprehensiveness of the scheme

- absence of errors in the implementation of the scheme

- comprehensiveness of the contents

- understandability of the contents

- expert support in the conversion of the place of learning into the place of functioning

- consideration of proposals for change

- level of complaints

While the above list is fairly all-inclusive, the exact criteria for the evaluation of training cannot be easily worked out. Ideally, customer-centred training providers should a) integrate both sets of expectations (of individuals and organisations) in the design of their training programmes and b) carry out systematic assessment of training to enable its further improvement. The latter, i.e. systematic improvement of training to address contemporary, fast emerging challenges of the oil and gas sector, would

International Journal of Management and Applied Research, 2015, Vol. 2, No. 3 
represent a balancing act between topicality and relevance in advancing training programmes.

In the review of quality issues and trends in vocational education and training in Europe, Van den Berghe (1996) maintains that the following aspects of accreditation should be considered and even prescribed by public authorities:

- recognition of the content and the certificates of vocational education and training programmes -notably those giving access to other programmes and positions in public services or regulated professions

- official standards for programmes and providers, in general referring to inputfactors

- regulated access requirements of trainees

- inspection systems

- qualification requirements of trainers and teachers

In the case of OGAS, the dominant approach would be in amalgamating the existing standards in developing and delivery of vocational training, maintained by the Scottish Credit and Qualifications Framework (SCQF) (2014) and safeguarded by the Scottish Qualifications Authority (SQA) (2014). This approach would ensure that all training and education providers have a shared starting point for setting, describing and assuring the academic standards and respective credit awards.

With respect to criteria for evaluation, the following checklist is suggested as a starting point in developing a more standardised evaluation of emerging trends and/or technical issues in the oil and gas industry:

- the competence, expertise and qualifications of the trainers

- the adequacy of the identification of training needs and the capacity in transforming the results of training needs analyses into relevant training plans and specifications

- the relevance of qualifications offered

- the effectiveness of the training in terms of achieving positive outcomes and performance improvements

- the usefulness and relevance of the training support materials and tools, as well as the suitability of the premises, equipment and environment for training

- the effectiveness of the organisation, procedures and training arrangements

(Adapted from Van den Berghe, 1996)

The aforementioned evaluation criteria are to be implemented by the means of credit rating, the process by which the SCQF level and SCQF credit points are allocated to certain units and qualifications (SQA, 2009). The benefits of such an approach are in establishing transparent relationships between qualifications, with learners being able to make the most of credit transfer opportunities and progression routes (SQA, 2015) in developing their own qualifications portfolio.

Participants who successfully complete an SCQF Credit Rating programme will own the qualification and, unlike in many other company training programmes, it will be "portable', i.e. associated with personal achievements rather than with the

International Journal of Management and Applied Research, 2015, Vol. 2, No. 3 
organisation's trainings and hence will belong to them for the rest of their career. This in turn will result in greater motivation and engagement with the training and education packages on the part of participants. The companies who commission people to take these programmes, because of the accreditation, will be able to place higher levels of confidence in the ability of the training or educational activity to deliver effectively the objectives of the course.

Figure 1 Relationships between Training providers and OGAS

\begin{tabular}{|c|c|}
\hline Training provider is expected to: & OGAS support includes: \\
\hline $\begin{array}{l}\text { - Identify learning needs or } \\
\text { business case } \\
\text { - Develop objectives for } \\
\text { learning programme } \\
\text { - Identify required learning } \\
\text { outcomes and assessment } \\
\text { methods } \\
\text { - Contact OGAS to discuss } \\
\text { programme } \\
\text { Programme delivery }\end{array}$ & $\begin{array}{l}\text { Feedback on proposed learning } \\
\text { programme } \\
\text { - } \quad \text { Validation of quality assurance } \\
\text { process and procedures } \\
\text { - Panel review and allocation of } \\
\text { level and credits } \\
\text { - Help with SCQF registration of } \\
\text { developed learning programme } \\
\text { Details of awarded certification to } \\
\text { individuals held in OGAS database } \\
\text { and accessible to employers }\end{array}$ \\
\hline
\end{tabular}

The OGAS SCQF credit rating process (Figure 1) will augment the existing provision of accreditation offered by professional bodies and by the Scottish Qualification Authority third party credit rating of Scottish Vocational Qualifications. OGAS is in a position to aggregate the unique specialist expertise through its partners' network, encompassing universities and colleges. Therefore the positioning of the Oil and Gas Academy of Scotland, coupled with the expertise and experience of partner organisations in all aspects of managing the quality of training and education, will provide a solid basis for reliable credit ranking, enabling portable and attractive qualifications classification.

\section{Conclusion}

The introduced process will facilitate the development of clear routes for further development of successful candidates through potential articulation between the accredited training and education units and formal qualifications available through Further and Higher Education Institutions. This process is in line with one of the eight key policy domains identified in the 'Education and Training 2020' framework: modernising vocational education and training (Europa, 2010). 


\section{References}

1. Europa (2010), Coherent framework of indicators and benchmarks [Online], available from:

http://europa.eu/legislation_summaries/education_training_youth/general_framewor k/c11099_en.htm (accessed on 13 March 2015)

2. Harvey, L. and Williams, J. (2010), "Fifteen Years of Quality in Higher Education", Quality in Higher Education, Vol. 16, No. 1, pp. 3-36.

https://doi.org/10.1080/13538321003679457

3. Lester, S. (2010), Principles of professional accreditation, [Online], available from: http://www.sld.demon.co.uk/accred.pdf (accessed on 20 March 2015).

4. Soares, L.; Eaton, J. S.; Smith, B. (2013), "Higher Education: New Models, New Rules", EDUCAUSE Review, Vol. 48, No. 5, pp. 69-87.

5. Scottish Credit and Qualifications Framework (SCQF) (2014), Guidelines to Promote and Support the Credit Rating Process in Colleges in Scotland [Online], available from: http://scqf.org.uk/wp-content/uploads/2014/05/Guidelines-toPromote-and-Support-Credit-Rating-Process-updated-FINAL-web.pdf (accessed on 20 March 2015).

6. Scottish Qualifications Authority (SQA) (2014), Credit Rating of SQA AccreditedQualifications for the Scottish Credit and Qualifications Framework, [Online], available from: http://www.sqa.org.uk/files_ccc/2014.04.28\%20Credit\%20Rating\%20Guide.pdf (accessed on 20 March 2015).

7. Scottish Qualifications Authority (SQA) (2015), SQA Credit Rating Service [Online], available from: http://www.sqa.org.uk/sqa/7597.html (accessed on 27 March 2015).

8. Scottish Qualifications Authority (SQA), (2009), Accreditation Definitions, within the context of $S Q A$, [Online], available from: http://www.sqa.org.uk/files_ccc/SVQUpdate.pdf(accessed on 20 March 2015).

9. Van den Berghe, W. (1996), Quality Issues and Trends in Vocational Education and Training in Europe, European Centre for the Development of Vocational Training. 